\title{
Data Validation
}

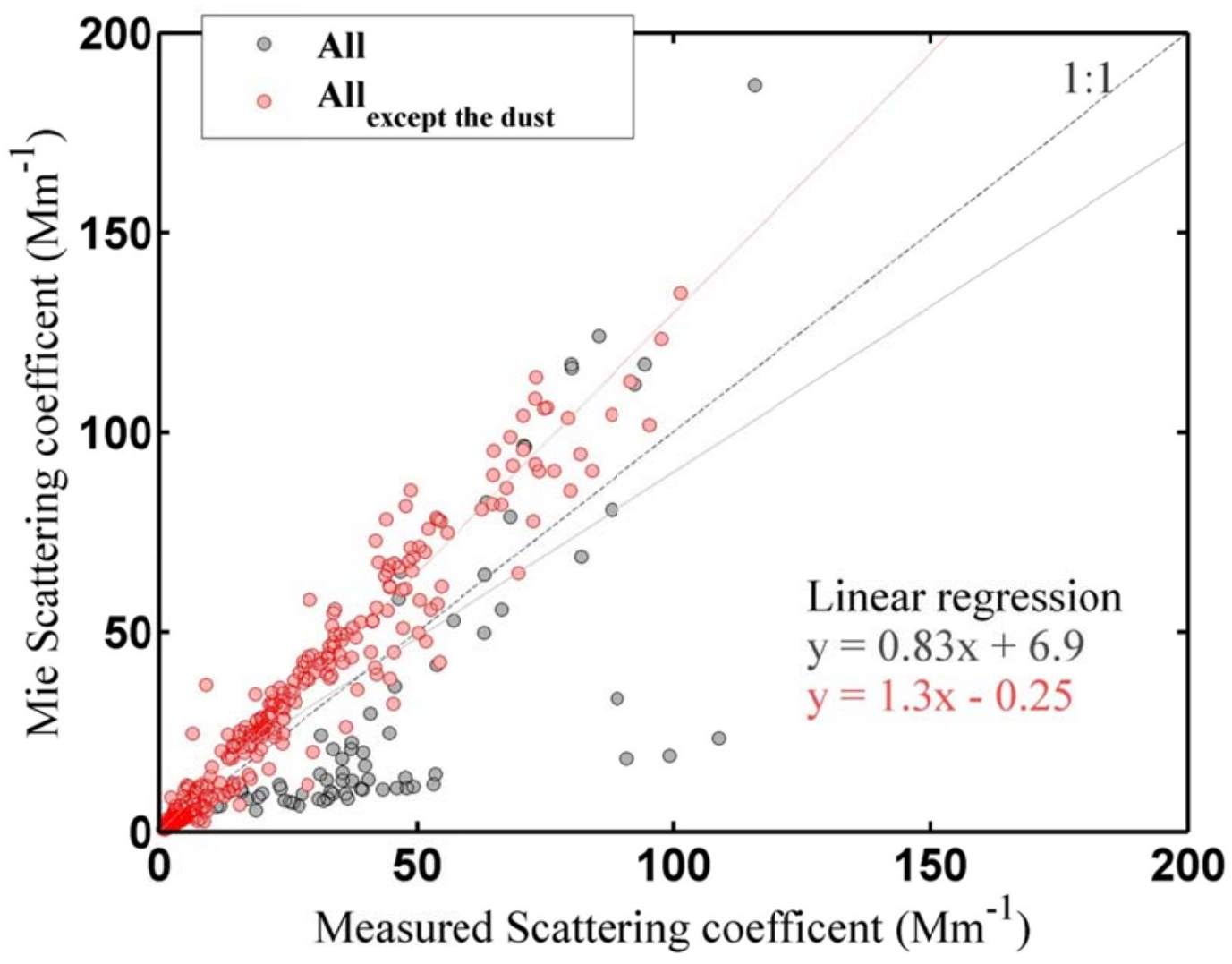

Figure 1 : Scattering coefficient measured by the nephelometer versus the scattering coefficient calculated using the Mie theory assuming an homogeneous aerosol population with spherical shape and assuming a refractive index of $1.55+0.01 \mathrm{i}$ 


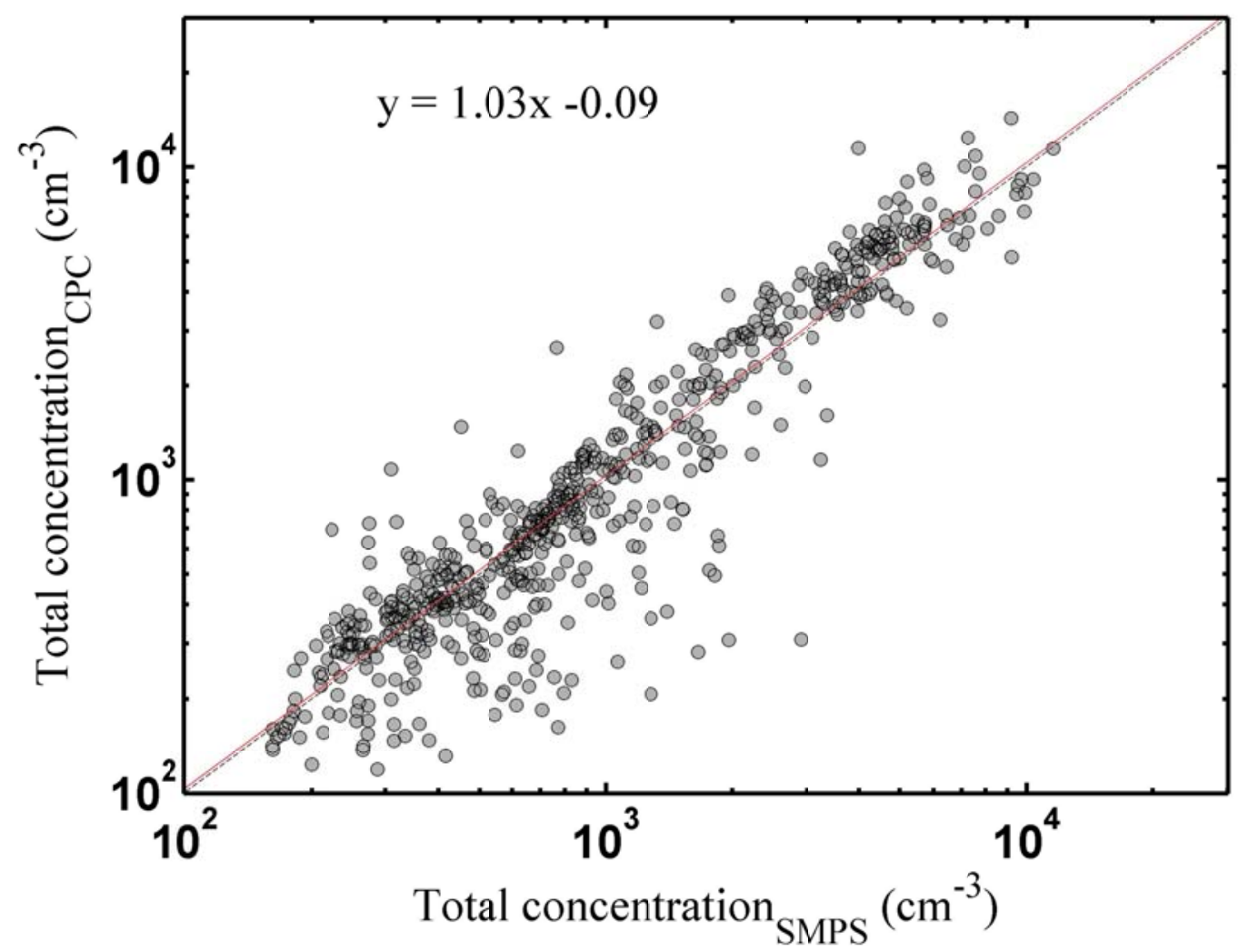

Figure 2 : Aerosol total concentration measured by the CPC as a function of aerosol total concentration measured by the SMPS. The dashed line represents the 1:1 line while the red line represent the linear regression. 